\title{
単一分子計測による高分子薄膜の物性評価
}

\author{
青 木 裕 之 \\ 京都大学先端医工学研究ユニット 恶 615-8510 京都府京都市西京区京都大学桂
}

（2011 年 10 月 22 日受付；2011 年 11 月 8 日揭載決定）

\section{Properties of Polymer Thin Films Studied by Direct Observation of Single Chains}

\author{
Hiroyuki AOKı
}

Advanced Biomedical Engineering Research Unit, Kyoto University

Nishikyo, Kyoto 615-8510

(Received October 22, 2011 ; Accepted November 8, 2011)

\begin{abstract}
Properties of polymer materials originate from the large degree of freedom of a single polymer chain. The direct observation of the conformation of single polymer chains would provide much information for the fundamental understanding of the properties of polymers. Fluorescence imaging techniques are suitable for the selective observation of individual molecules embedded in a bulk medium; however, the spatial resolution of conventional optical microscopy is limited to $\sim 200 \mathrm{~nm}$ by the diffraction limit. This paper reviews the state-of-the-art optical imaging techniques that enable to obtain a fluorescence image with a nanometoric spatial resolution and describes its application for the direct imaging of the conformation of individual polymer chains. The conformation of poly(alkyl methacrylate) chains in thin films and micro-phase separation structures of a block copolymer is discussed.
\end{abstract}

KEYWORDS : polymer, single molecule, near-field optics, super-resolution technique, fluorescence microscopy

\section{1.は じめに}

高分子化合物は鎖状の巨大分子であり，その大きな分 子内自由度のために様々な形態（コンホメーション）を とることができる。このような自由度の大きさが高分子 特有の物性を示す起源となる。そのため, 高分子鎖のコ ンホメーションについては古くから研究が行われてき た ${ }^{1,2)}$ 。高分子材料の表面 - 界面, 薄膜状態においては バルクとは異なった物性が発現することが知られている が，これは界面の存在によって高分子鎖の自由度が空間 的に制限されていることが大きな要因の一つであると考 えられる。このような高分子材料の界面・薄膜物性を明 らかにするにあたり, 高分子鎖一本一本のコンホメーシ ヨンを直接的に実空間観察し，またその時間変化を追跡 することが可能となれば, 材料の物性発現のメカニズム を理解するための重要な情報を与えるものと考えられ る。実在の高分子材料は多数の高分子鎖で構成されてお

E-mail : aoki@photo.polym.kyoto-u.ac.jp
り，また鎖同士は互いに複雑に絡まり合っている。この ような高分子鎖一本のコンホメーションを評価するため には，バルク中の複数の鎖の中から一本のみを選択的に 観察する必要がある。このような計測を実現する手法と しては蛍光ラベル法が最も有効であると考えられる。試 料に微量の蛍光色素分子を導入（蛍光ラベル）し，その 蛍光発光を顕微鏡観察することでラベルした試料のみの 構造を選択的に実空間観察することができる。しかしな がら従来の光学顕微鏡では空間分解能が回折限界によっ て制限されており, 高々 $100 \mathrm{~nm}$ 程度の拡がりしか持た ない高分子鎖のコンホメーションを直接観察することは 不可能であった。しかし，最近になって光を用いながら ナノメートルスケールの空間分解能での光学イメージン グを実現する近接場光学顕微鏡 ・ 超解像顕微鏡, また単 一分子の三次元配向評価を可能にするデフォーカス観察 法などが提案され，これまでにない情報を得ることがで きるようになっている。本稿ではこのような最近の蛍光 顕微鏡技術の発展について紹介し，高分子の分子レベル での物性評価への応用について述べる。 


\section{2. 回折限界を超える光学顕微鏡}

\section{1 近接場光学顕微鏡}

光学顕微鏡は光をレンズによって集光することで画像 化を行っているが, 回折の影響により光を無限小の点に 集光することはできず, 波長の半分程度のサイズに広が る (回折限界)。そのため可視光領域では $200 \mathrm{~nm}$ 以下 に近接した二つの物体は重なって観察され，見分けるこ とが不可能となる。一方, 光を波長以下の微小構造に照 射すると, その近傍にのみ束縛された近接場光が発生す る。このような近接場光を用いて試料を照明するのが走 查型近接場光学顕微鏡 (SNOM) である ${ }^{3,4)}$ 。SNOM は 走查型プローブ顕微鏡の一種であり, Fig. 1 (a) に示す ような微小開口を有する探針を用い, そこに発生した近 接場光を照射し, 試料からの信号光を検出する。その空 間分解能は近接場光の局在によって決まり, 概ね 50$100 \mathrm{~nm}$ となる。SNOM では信号光の検出に蛍光分光や ラマン散乱分光, 偏光測定など様々な分光法を適用する ことができ, 回折限界を超える空間分解能で多彩な情報 を得ることができる。

Fig. 1（b）にポリメタクリル酸メチル（PMMA）鎖の 単一分子鎖を観察した SNOM 像を示す5)。これは PMMA 鎖の側鎖メチル基の $0.8 \%$ に蛍光色素であるぺリ レンで置換することでラベルした鎖を，蛍光ラベルして いないPMMAのマトリックス中に分散した試料を測定 したものである。このような試料を用いることで PMMA のバルクの中でラベルした PMMA 鎖のみを選択

(a)

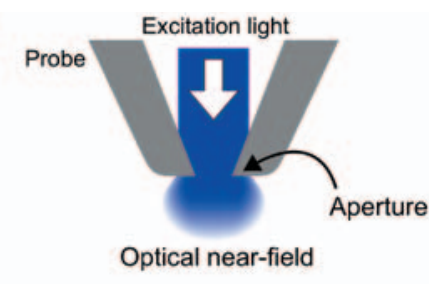

(b)

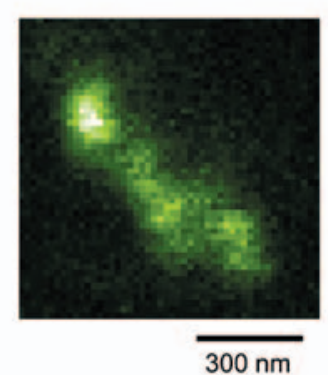

Fig. 1. (color online). Schematic illustration of SNOM probe emanating optical near-field (a) and SNOM image of a single chain of poly(methyl methacrylate) (b).
的に観察することができる。通常の光学顕微鏡では明確 に捉えることが不可能なサイズの高分子鎖のコンホメー ションを, SNOM では明瞭に観察できていることがわ かる。以上のように蛍光ラベル法と高分解能の光学イメ ージングを用いることでバルク内の高分子鎖一本のコン ホメーションを実空間で評価することができるようにな つた。

\section{2 超解像蛍光顕微鏡}

超解像光学はナノメートルスケールの分解能を達成す る手法の一つとして近年注目を集めている。上に述べた ように近接場光学顕微鏡は光そのものをナノメートルス ケールの空間に閉じ込めることで, 直接的に光学像の分 解能を高めようとするものである。これ対して超解像光 学顕微鏡は回折限界によって制限された従来の光学系を 用いながら, 測定法やデー夕解析によって高解像の情報 を抽出するものである。ここでは単一分子検出に基づく 超解像顕微鏡法について述べる。

近年の高感度 CCD カメラを用いることにより, 強い 蛍光を発する色素であれば分子一個を蛍光顕微鏡によっ て容易に観察できるようになった。このとき単一分子の 蛍光画像は回折限界によって広がった輝点として観察さ れるため, 近接した二つの分子を識別可能であるか否か という基準においては光学顕微鏡の分解能は $200 \mathrm{~nm}$ 程 度と見なされる。しかし視野内に一つの分子しか存在し ない場合, その中心の位置を決定する精度は非常に高い ことが知られており, その位置決定の分解能は $10 \mathrm{~nm}$ 以下にも及ぶ。このような手法はしばしば FIONA（Fluorescence Imaging with One-Nanometer Accuracy）と呼ば れる6)。

蛍光イメージングにおいては, 観察対象となる構造物 に対して蛍光色素分子を複数結合し, それらの空間分布 を画像として観察する。従来の蛍光顕微鏡観察では全て の分子を同時に発光させ，これを結像するため近接した 分子同士を解像できない。しかし色素分子のうち，ただ 一個だけを発光させて, その位置を FIONAによって取 得すれば, 色素分子の座標を数 $\mathrm{nm}$ の分解能で決定でき ることになる。そしてこのプロセスを繰り返して, 全て の色素分子について位置座標を一つ一つ順番に測定し, それらの座標データを一枚の面内にプロットすること で，再構築画像を作成することができる。このようにし て得られる蛍光画像の空間分解能は分子の位置決定精度 すなわち数 $\mathrm{nm}$ によって決定され, 非常に高い分解能で の蛍光イメージングを実現することが可能となる。その 测定プロセスを Fig. 2 に模式的に示す。このような測定 を実現するためには, 発光状態を任意に制御することが できる色素分子が必要であるが，そのためにしばしばフ 
(a) Fluorescence (b) Reconstruction image

1.

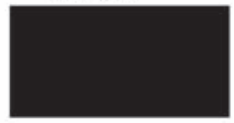
image

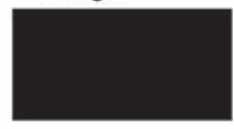

2.
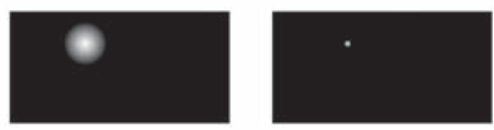

3.
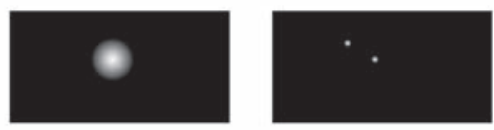

4.
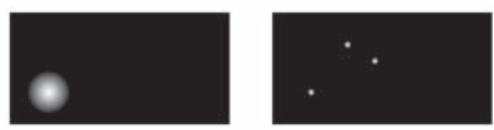

5.
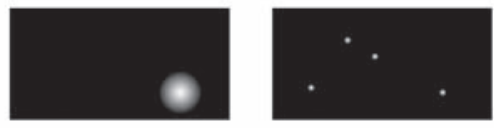

6.
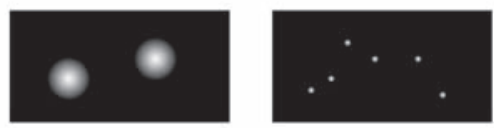

7.
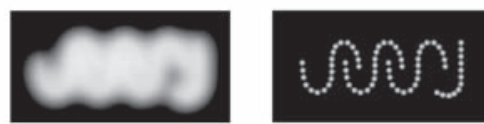

Fig. 2. Schematic process of photo-activated localization microscopy. The left-hand side (a) indicates the fluorescence image of individual dye molecules. The right-hand side (b) indicates the reconstruction images, which shows the position of the dye molecules analyzed from the fluorescence image. The panel $7 \mathrm{a}$ is a superimposition of fluorescence images of individual dye molecules, which corresponds to a conventional fluorescence image. The panel $7 \mathrm{~b}$ indicates the super-resolution image.

オトクロミック性色素が用いられる7)。フォトクロミッ ク色素は二つの異性体を持ち，一方は蛍光性，他方は非 蛍光性である。異性体間の変換は紫外光の照射によって 行われ，まず最初に全ての分子を非蛍光体に変換し，蛍 光画像内に色素分子が観察されない状態とする（Fig. 2 中 1 (a))。ここに弱い紫外光を照射することで, 色素 分子のうち一個だけが蛍光体へと変換され, Fig. 2 中 2 (a) のように蛍光画像として観察される。その画像から 色素分子の位置を解析し, その座標を再構築画像中に記 録する (Fig. 2 中 $2(b)) 。 一$ 度観察した分子は, 強い励 起光で裉色あるいは再び非蛍光体へ変換することで消去 する。その後, 再び紫外光を照射することで別の分子を 観察・座標解析を行う (Fig. 2 中 3 (a), (b))。このよ うなプロセスを繰り返すことで，最終的には Fig. 2 の 7 （b）のような高分解能の蛍光画像を得ることが可能とな る。このような手法は PALM (Photo-Activated Localization Microcopy) あるいは STORM (Stochastic Optical Reconstruction Microscopy) と呼ばれ ${ }^{8,9)}$, 特に生物分野 での応用が盛んに研究されているが, 近年では単一高分 子鎖の形態観察への展開も行われている ${ }^{10)}$ 。

\section{3 単一分子の三次元配向イメージング}

単一分子観察において得られるのは, 分子の位置情報 であった。しかし観察法を工夫することで，個々の分子 の三次元配向すなわち極角 $\theta$ と方位角 $\varphi($ Fig. $3(\mathrm{a}))$ を得ることもできる。分子一個の配向状態は蛍光強度の 角度依存性から見積もることができるが，放射角分布は 顕微鏡測定において焦点位置をシフトさせることで容易 に計測することができる ${ }^{11)}$ 。Fig. 3（b）は単一のペリレ ンジイミド分子の蛍光顕微鏡画像であり, 回折限界程度 の大きさ $200 \mathrm{~nm}$ の円形に観察されている。これは焦点 の合った状態の画像であるが，この状態から顕微鏡対物 レンズを $1 \mu \mathrm{m}$ シフトさせて撮影した蛍光画像が Fig. 3 (c) である。このようにデフォーカス条件で観察された 分子は配向角に依存した特有のパターンを示しているこ

(c)

(a)

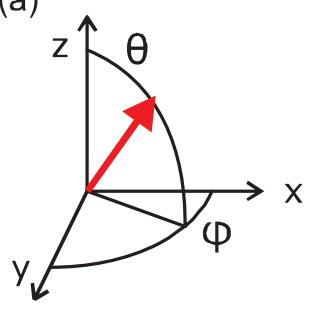

(b)

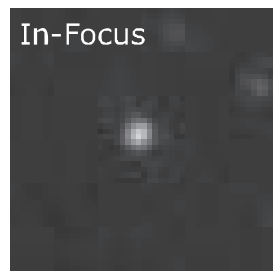

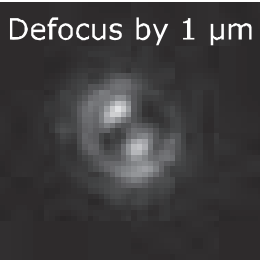

(d)

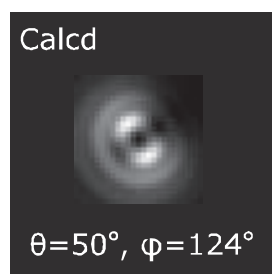

Fig. 3. (color online). Coordinate system of single molecule (a), the fluorescence microscope images of a single perylene diimide dye molecule in the in-focus (b) and out-of-focus conditions (c), and the calculated defocus pattern (d). The red arrow in the panel (a) indicates the transition moment. 
とがわかる。このデフォーカスパターンは理論計算によ って生成することができ, 実験データに対してフィッテ イングを行うことで分子の三次元配向パラメータ $(\theta$, 甲）を見積もることができる。これにより高分子鎖のコ ンホメーションだけでなく，単一のセグメントの配向状

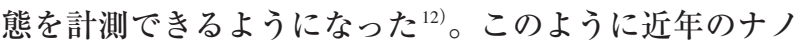
光学イメージング技術の発展により, 高分解能かつ分子 配向の直接計測などこれまでにない情報が得られるよう になっている。

\section{3. 単一高分子鎖のコンホメーション解析}

\section{1 薄膜中の高分子鎖}

薄膜中における高分子鎖は，空気と接する表面とガラ ス基板との二つの界面の間で空間的拘束を受けている。 このような鎖のコンホメーションについては，これまで にも中性子散乱などによって研究されてきたが，その実 体は十分に明らかにはなっていなかった。そこで高分解 能の光学イメージングによる実像観察によって直接的に 薄膜中のコンホメーション評価を行う試みがなされ た ${ }^{5)}$ 。

PMMA を試料として用い, 分子鎖の回転半径よりも 十分に小さい超薄膜から三次元バルクとみなせる厚膜の 試料を作製し，その中での PMMA 鎖一本の形態を直接 評価した。SNOMによる観察を行うため，PMMAの側 鎖メチル基の約 $0.8 \%$ を蛍光色素であるペリレンによっ て置換した高分子を合成した $\left(M_{n}=4.16 \times 10^{6}, \mathrm{PDI}=\right.$ 1.23）。これを蛍光ラベルを施していないPMMA に極微 量混合し，スピンキャスト法により膜厚 7-100 nm の薄 膜試料を作製した。また鎖が二次元状態で広がった系と して Langmuir-Blodgett 法による単分子膜を作製した。

SNOM 測定により，Fig. 2（b）に示すような個々の PMMA 鎖のコンホメーションが観察されるが，定量的 に鎖の拡がりを評価するため，SNOMによって観察さ れた個々の鎖について, 次式で定義される鎖の拡がり $R_{x y}{ }^{2}$ を見積もった。

$$
\begin{aligned}
& R_{x y}{ }^{2}=\frac{\sum_{i} I_{i}\left(\mathbf{r}_{i}-\mathbf{r}_{\mathrm{cm}}\right)^{2}}{\sum_{i} I_{i}} \\
& \mathbf{r}_{\mathrm{cm}}=\frac{\sum_{i} I_{i} \mathbf{r}_{i}}{\sum_{i} I_{i}}
\end{aligned}
$$

ここで $\mathbf{r}_{i}, I_{i}$ はそれぞれ SNOM 像中 $i$ 番目の画素の位置 ベクトルおよび蛍光強度であり， $\mathbf{r}_{\mathrm{cm}}$ は重心の位置べク トルを表している。このようにして見積もられる $R_{x y}{ }^{2}$ は，高分子鎖の薄膜平面上への射影についての回転二乗 半径に相当する。様々な膜厚の試料に対して鎖一本一本 の回転半径を算出した結果を Fig. 4 のヒストグラムに示 す。SNOM によって個々の PMMA 鎖を直接観察するこ

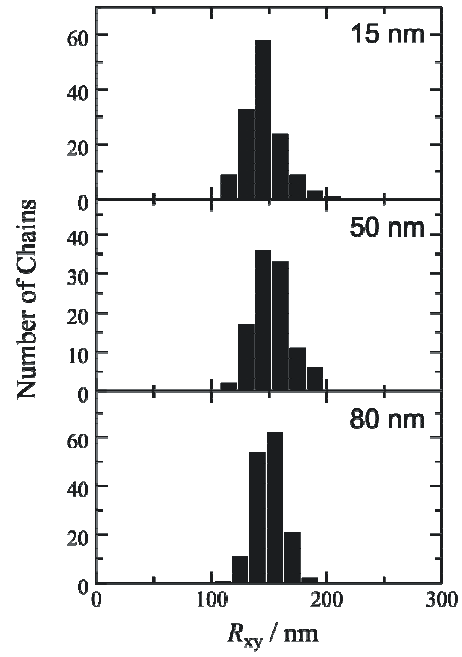

Fig. 4. Histograms of the chain dimension of the PMMA chain in thin films.

とで，鎖の拡がりの分布関数を直接的に得ることが可能 である。ここでは膜厚 $15,50,80 \mathrm{~nm}$ についての $R_{x y}$ を 示しているが，この図から PMMA 鎖の $R_{x y}$ の分布関数 の形状は膜厚に依存しておらず，その平均值 $\left\langle R_{x y}\right\rangle$ は 約 $140 \mathrm{~nm}$ で一定であることがわかった。さらに鎖が二 次元に束縛された単分子膜についても同様に測定を行っ たところ，〈R $\left.R_{x y}\right\rangle$ は $139 \mathrm{~nm}$ であった。このように膜厚 が鎖の非摂動状態でのサイズと同程度以下の超薄膜領域 において〈 $\left.R_{x y}\right\rangle$ が膜厚に依存しないことが示された。 そこで鎖の拡がりに対して十分に膜厚が大きく，バルク 状態と見なすことが可能な試料について同様の測定を行 ったところ, その拡がりは $138 \mathrm{~nm}$ と見積もられ, 超薄 膜状態と比較してもほぼ同程度の $R_{x y}$ を示すことがわか った。この結果，高分子鎖はバルク状態から高さ方向の 空間的制限を受けた超薄膜状態になっても，Fig. 5 に示 すように薄膜面内方向の拡がりが変化しないことが明ら かとなった。バルク状態では高分子鎖は三次元的に拡が ったコンホメーションをとっており, 周囲の鎖とのから み合いを形成している。高さ方向の拘束下においても高 分子鎖が水平方向に拡がらないということは, 鎖が収縮 した形態をとることを意味しており，Fig. 5（b）に示さ れるように超薄膜中において高分子鎖は他の鎖との絡み 合いを形成しないものと考えられる。これはde Gennes によって子測された二次元平面における高分子鎖のコン ホメーションの描像を支持するものであり ${ }^{1)}$, このよう なモデルによって薄膜の巨視的な物性もうまく説明する ことができる ${ }^{13,14)}$ 。のように SNOM を用いて高分子 鎖一本一本を直接観察することで, 超薄膜中における特 徴的な分子鎖の形態が明らかとなった。 
(a)

(b)
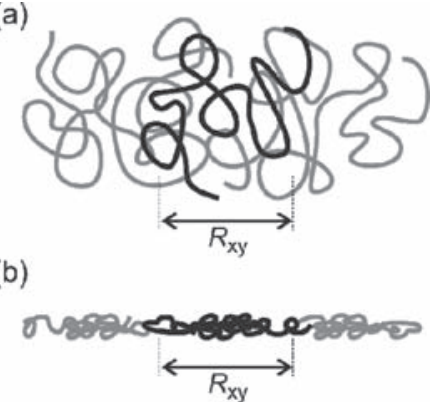

Fig. 5. Schematic illustration of the conformation of polymer chains in a three-dimensional bulk state (a) and an ultra-thin film (b).

\section{2 ミクロ相分離構造内の高分子鎖}

ブロック共重合体が示すミクロ相分離構造中における 高分子鎖も，薄膜と同様に空間的に自由度を制限された 状態にあると考えることができる。ミクロ相分離構造中 の鎖のコンホメーションについてはこれまでに理論的, 実験的に精力的に研究が行われてきたが，そのコンホメ ーションを実空間において評価した例はない。本節で は, A-B 型ブロック共重合体のミクロ相分離構造中に分 散した A ホモポリマーについて，その形態を評価した 研究について述べる ${ }^{15)}$ 。

試料としてポリスチレン（PS）および PMMA のブロ ック共重合体（PS-PMMA）を用い,ここに極微量の PMMA ホモポリマー鎖を混合し, 溶媒キャストの後に 十分にアニーリングすることでミクロ相分離構造を形成 した。PS-PMMA のそれぞれの成分の分子量は $M_{n, \mathrm{PS}}=$ $8.68 \times 10^{5}, M_{n, \text { PMMA }}=8.57 \times 10^{5}$ とほぼ同じであり, ラメ ラ型のミクロ相分離構造を示した。この系中に蛍光ラべ ルを施した分子量 $1.7 \times 10^{6}$ の PMMA ホモポリマーを分 散し，その単一分子鎖を SNOM によって観察すること で，ミクロ相分離構造内における位置と配向を評価し た。

Fig. 6 にPS-PMMA の SNOM 像を示す。Fig. 6 (a) は 励起光の散乱強度をマッピングすることで得られた SNOM 像であり, PS-PMMA のラメラ状ミクロ相分離構 造が観察され，その周期は $160 \mathrm{~nm}$ であることがわかっ た。図中の明暗の領域はそれぞれ PMMA およびPS ド メインに相当する。Fig. 6 （b）は同時に得られたペリレ ン蛍光像であり, ミクロ相分離ドメイン内に分散した単 一の PMMA ホモポリマーが観測されている。両者の画 像を比較すると, PMMA ホモポリマーはPS-PMMA 相 分離構造の PMMA ドメイン内に存在していることがわ かる。より詳細な解析を行うために個々の鎖について得 られた SNOM 画像を楕円によって近似し（Fig.7（a））,
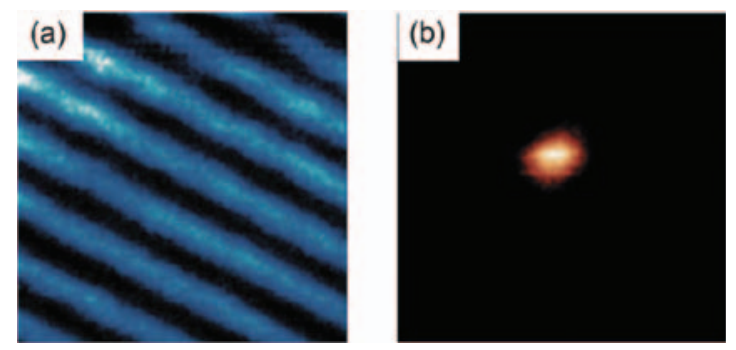

Fig. 6. (color online). SNOM images of the micro-phase separation structure of PS-PMMA containing small amount of homo-PMMA. The panel (a) was acquired by collecting the scattered light. The bright and dark parts indicate the PMMA and PS domains, respectively. The panel (b) is the fluorescence image, where the single chain of homo-PMMA was selectively observed. (a)

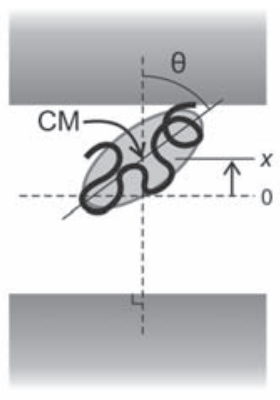

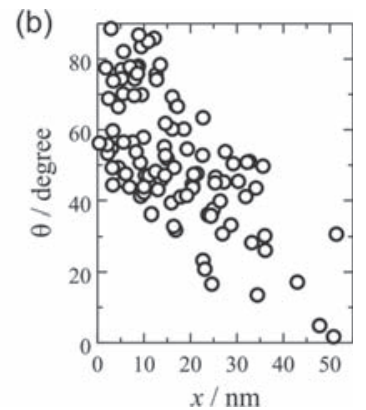

Fig. 7. Schematic drawing of the homo-PMMA chain doped in the micro-phase separation structure of PSPMMA (a) and the plot of the conformational orientation against the chain position (b). The position $x$ is defined as the distance between the center of mass $(\mathrm{CM})$ of the chain and the middle of the PMMA domain. The chain orientation $\theta$ indicates the angle between the normal of the phase boundary and the long axis of the fitted ellipse for the homopolymer chain.

その重心位置および相分離界面に対する鎖の配向角 $\theta$ を見積もった。ミクロ相分離構造内における PMMA ホ モポリマーの重心位置を詳細に検討したところ, PMMA ホモポリマー鎖のほぼ全てが PMMA ドメイン内 に局在しており, 特にドメイン中央部に偏在しているこ とが明らかとなった。次に相分離界面に対するホモポリ マー鎖の配向を評価するため, Fig. 7 (b) に PMMA ド メイン中心からホモ PMMA 鎖までの距離 $x$ と配向角 $\theta$ の関係を示す。この図から PMMA ドメイン中央に位置 する PMMA ホモポリマー鎖は相分離界面に対して平行 な配向を示す傾向があることがわかった。

A-B ブロック共重合体/A-ホモポリマー混合系の相分 離構造内におけるホモポリマー鎖の分布はブロック共重 
合体中の $\mathrm{A}$ 鎖および $\mathrm{A}$ ホモポリマーの分子量に依存す ることが知られており，ホモポリマーの分子量がブロッ ク鎖よりも大きな場合, A ホモポリマーが A ドメイン から排斥されることが知られている。ここで用いた PMMA ホモポリマーはブロック鎖に対して二倍の分子 量を持つため, ラメラ PMMA ドメインから排除され中 央に偏在する。その結果, ドメイン界面に対して平行に 伸張したコンホメーションをとるものと考えられる。一 方, 相分離界面近傍に存在するホモポリマー鎖も少数な がら存在するが，このような鎖は界面に対して垂直に伸 張したコンホメーションをとることが明らかとなった。 ブロック共重合体鎖は相分離界面に対して垂直に伸張し た形態をとっていることが知られているが, 界面近傍に おいて PMMA ホモポリマー鎖はブロック共重合体鎖の 影響を受けて界面垂直方向に配向するものと考えられ る。またホモポリマーだけでなくブロック鎖のコンホメ ーションの直接観察も行われている ${ }^{16,17)}$ 。このように 個々の鎖を直接観察することにより，ミクロ相分離構造 中に拘束された高分子鎖の形態について詳細な情報を得 ることが可能となった。

\section{4. ま め}

回折限界を超える新しい光学イメージングによる単一 分子蛍光観察法が開発され，表面・界面での高分子鎖の コンホメーションを直接的に評価することができるよう になった。このような実空間観察法に時間軸を加えるこ とで，高分子鎖の運動の様子を直接とらえることも可能 になっている ${ }^{18,19)}$ 。これまでに確立された分光法や散乱 法にあわせて, このような高分解能光学イメージングに よる単一高分子鎖の実空間観察が加わることで高分子の すがたをより鮮明に描き出すことが可能になるものと期 待される。ここで紹介した SNOM や PALM だけでなく 構造化照明や誘導放出過程を利用した手法も提案さてお り, 超高解像の光学イメージング法は高分子界面の物性 研究において大きな役割を果たすものと考えられる。

\section{文献}

1) P.G. de Gennes : "Scaling Concepts in Polymer Physics" (Cornell University Press, Ithaca, New York, 1979).

2) M. Doi and S.F. Edwards: "The Theory of Polymer Dynamics" (Clarendon, Oxford, 1986).

3) E. Betzig and J.K. Trautman : Science 257, 189 (1992).

4) M. Ohtsu (Ed.) : "Near-field Nano/Atom Optics and Technology” (Springer, Tokyo, 1998).

5) H. Aoki, S. Morita, S. Sekine and S. Ito : Polym. J. 40, 274 (2008).

6) A. Yildiz, J.N. Forkey, S.A. McKinney, T. Ha, Y.E. Goldman and P.R. Selvin : Science 300, 2061 (2003).

7) T.J. Gould, V.V. Verkhusha and S.T. Hess : Nat. Protocols 4, 291 (2009).

8) E. Betzig, G.H. Patterson, R. Sougrat, O.W. Lindwasser, S. Olenych, J.S. Bonifacino, M.W. Davidson, J. Lippincott-Schwartz and H.F. Hess : Science 313, 1642 (2006).

9) M.J. Rust, M. Bates and X. Zhuang : Nat. Methods 3, 793 (2006).

10) H. Aoki, K. Mori and S. Ito : Polym. Prepr. Jpn. 59, 4447 (2010).

11) M. Bohmer and J. Enderlein : J. Opt. Soc. Am. B Opt. Phys. 20, 554 (2003).

12) H. Aoki, T. Takahashi and S. Ito : Polym. J. 43, 218 (2011).

13) N. Sato, S. Ito and M. Yamamoto: Macromolecules 31, 2673 (1998).

14) L. Si, M.V. Massa, K. Dalnoki-Veress, H.R. Brown and R.A.L. Jones : Phys. Rev. Lett. 94, 127801 (2005).

15) J. Yang, R. Sekine, H. Aoki and S. Ito : Macromolecules 40, 7573 (2007).

16) R. Sekine, H. Aoki and S. Ito: J. Phys. Chem. B 113, 7095 (2009).

17) Y. Tamai, R. Sekine, H. Aoki and S. Ito : Macromolecules 42, 4224 (2009).

18) T. Ube, H. Aoki, S. Ito, J. Horinaka, T. Takigawa and T. Masuda : Polymer 50, 3016 (2009).

19) T. Ube, H. Aoki, S. Ito, J. Horinaka, T. Takigawa and T. Masuda : Macromolecules 44, 4445 (2011). 